\title{
hBN Nanoparticle-Assisted Rapid Thermal Cycling for the Detection of Acanthamoeba
}

\author{
Abdul Khaliq Rasheed ${ }^{1}{ }^{(0)}$, Ruqaiyyah Siddiqui ${ }^{2}{ }^{(0)}$, Salma Mohammed Kabir Ahmed ${ }^{3}$, \\ Shobana Gabriel ${ }^{3}$, Mohammed Zayan Jalal ${ }^{4}$, Akbar John ${ }^{5}(1)$ and Naveed Ahmed Khan ${ }^{2, *}$ (C) \\ 1 Department of New Energy Science and Engineering, School of Energy and Chemical Engineering, \\ Xiamen University Malaysia Campus, Bandar Sunsuria, Sepang 43900, Malaysia; \\ abdulkhaliq.rasheed@xmu.edu.my \\ 2 Department of Biology, Chemistry and Environmental Sciences, College of Arts and Sciences, American \\ University of Sharjah, Sharjah 26666, UAE; rsiddiqui@aus.edu \\ 3 Department of Biological Sciences, School of Science and Technology, Sunway University, Bandar Sunway \\ 47500, Malaysia; m.salma2015@hotmail.com (S.M.K.A.); shobygurl.gabriel@gmail.com (S.G.) \\ 4 Department of Mechanical Engineering, Faculty of Engineering, International Islamic University Malaysia, \\ Jalan Gombak 53100, Malaysia; zayan_mohammed@yahoo.co.in \\ 5 Institute of Oceanography and Maritime Studies, Kulliyyah of Science, International Islamic University \\ Malaysia, Kuantan 25200, Malaysia; akbarjohn@iium.edu.my \\ * Correspondence: naveed5438@gmail.com; Tel.: +971-6515-4752
}

Received: 13 August 2020; Accepted: 3 October 2020; Published: 7 October 2020

\begin{abstract}
Acanthamoeba are widely distributed in the environment and are known to cause blinding keratitis and brain infections with greater than $90 \%$ mortality rate. Currently, polymerase chain reaction (PCR) is a highly sensitive and promising technique in Acanthamoeba detection. Remarkably, the rate of heating-cooling and convective heat transfer of the PCR tube is limited by low thermal conductivity of the reagents mixture. The addition of nanoparticles to the reaction has been an interesting approach that could augment the thermal conductivity of the mixture and subsequently enhance heat transfer through the PCR tube. Here, we have developed hexagonal boron nitride $(\mathrm{hBN})$ nanoparticle-based PCR assay for the rapid detection of Acanthamoeba to amplify DNA from low amoeba cell density. As low as $1 \times 10^{-4}$ wt $\%$ was determined as the optimum concentration of hBN nanoparticles, which increased Acanthamoeba DNA yield up to $\sim 16 \%$. Further, it was able to reduce PCR temperature that led to a $\sim 2.0$-fold increase in Acanthamoeba DNA yield at an improved PCR specificity at $46.2^{\circ} \mathrm{C}$ low annealing temperature. $\mathrm{hBN}$ nanoparticles further reduced standard PCR step time by $10 \mathrm{~min}$ and cycles by eight; thus, enhancing Acanthamoeba detection rapidly. Enhancement of Acanthamoeba PCR DNA yield is possibly due to the high adsorption affinity of hBN nanoparticles to purine (Guanine-G) due to the higher thermal conductivity achieved in the PCR mixture due to the addition of $\mathrm{hBN}$. Although further research is needed to demonstrate these findings in clinical application, we propose that the interfacial layers, Brownian motion, and percolation network contribute to the enhanced thermal conductivity effect.
\end{abstract}

Keywords: nanoPCR; hexagonal boron nitride; thermal conductivity; Acanthamoeba; pathogen; bio-heat transfer

\section{Introduction}

Acanthamoeba is a free-living protozoan widely found in the environment. Despite being ubiquitous, they can survive as parasites to proliferate within human or animal tissues leading to two major life-threatening infectious diseases known as granulomatous amoebic encephalitis (GAE) and Acanthamoeba keratitis (AK) that often arise as mild headaches $[1,2]$. Microscopic-based detection methods are widely 
used in many countries to detect Acanthamoeba; however, these assays are labour intensive, time-consuming, and require Acanthamoeba culturing for up to several days [2-4]. Recent advances in the Acanthamoeba detection technique employs polymerase chain reaction (PCR) assay for the sensitive and rapid detection of Acanthamoeba parasites at the genotypic-level [5,6]. PCR technique involves three major steps: denaturation, annealing, and extension to amplify DNA. The DNA polymerase is the crucial ingredient in PCR to synthesize new DNA strands. Despite 90\% sensitivity and 90.8\% specificity of PCR assay in Acanthamoeba detection [3-6], the challenges of PCR technique include insufficient target DNA yield and non-specific DNA amplification leading to possible band smearing on gels [7]. Previously, Acanthamoeba detection used hot-start DNA polymerase enzymes to modify the conventional PCR techniques, avoiding non-specific amplification, and increasing the target DNA yield by inactivating the enzyme at lower temperatures [8]. However, these findings reported $82 \%$ specificity, suggesting a possible presence of undesired PCR products as false positives [8]. Additional PCR enhancers used to modify conventional PCR and increase target DNA yield include betaine to amplify GC rich long DNA and dimethyl sulfoxide (DMSO) to improve PCR specificity. However, $2 \%$ DMSO addition requires more enzyme because it can inhibit Taq DNA polymerase enzyme in the PCR reaction, affecting the fidelity of the PCR enzyme [9]. Hence, optimizing a PCR technique along with its parameters, is currently a time-consuming technique to obtain an enhanced target DNA yield.

Nanotechnology has emerged with the nanomaterial-assisted PCR (NanoPCR) technique, which introduces nanomaterials into the PCR mixture tto enhance PCR thermal conductivity. Since heat transfer limitation exists in the conventional PCR thermal cycler and is known to reduce PCR reaction efficiency, nano-PCR can address this issue by combining nanomaterials with excellent thermal conductivity properties into a PCR reaction to selectively increase target DNA yield and enhance PCR efficiency [10]. Nanoparticles ranging from 1 to $100 \mathrm{~nm}$ in size provide a conducive interface for DNA interactions due to the high surface area to volume ratio. Since nanoparticles possess unique physicochemical properties, significantly higher thermal conductivity, they are efficient PCR enhancers [11]. Graphene nanoparticle was proven to not only enhance PCR specificity but also maintain its fidelity [12]. $\mathrm{hBN}$ is an analogue of graphene and exists as a white crystalline solid compound within an ordered arrangement of Boron and Nitrogen atoms in a two-dimensional plane, giving rise to its most stable hexagonal honeycomb layered structure. Hence, the property of hexagonal boron nitride (hBN) is of interest as a potential nanomaterial because of characteristic resemblance to its analogue called graphene. hBN compound is inert and does not oxidize in air up to $900{ }^{\circ} \mathrm{C}$. It possesses high thermal conductivity and is non-toxic in the environment [13], making it highly suitable as a nanoparticle to enhance PCR efficiency.

\section{Nanoparticle Enhanced Thermal Conductivity}

Heat transfer through any liquid depends on its thermal conductivity. PCR reagents, which are water-like substances, have a thermal conductivity of approximately $0.6 \mathrm{Wm}^{-1} \mathrm{~K}^{-1}$. Rate of heating-cooling in PCR tubes is therefore limited by this property of PCR reagents. From an engineering perspective, the only way to address this problem is by introducing substances that have higher thermal conductivities into the PCR reagents. The idea of combining solid-liquid thermal conductivities for higher heat transfer has evolved from the time of Maxwell [14] (Equation (1)) and continues to improve until today.

$$
K_{e f f}=\frac{k_{p}+2 k_{b}+2\left(k_{p}-k_{b}\right) \varnothing}{k_{p}+2 k_{b}-2\left(k_{p}-k_{b}\right) \varnothing} k_{b}
$$

where $k_{\text {eff }}$ is effective thermal conductivity, $k_{p}, k_{b}$, and $\varnothing$ are the thermal conductivity of particle, the thermal conductivity of the base fluid, and the volume fraction, respectively. Early efforts failed as the methods were limited to producing micro-sized particles of metals and their densities were higher than the base fluids, causing immediate sedimentation. However, towards the end of the 20th century, nanomaterials were successfully dispersed in to liquids, and that resulted in an anomalous increase in the thermal conductivity. The increase in thermal conductivity is attributed to the Brownian 
motion of particles, molecular level layering at the liquid-particle interface, nanoparticle clustering [15], the formation of percolation network, and so on [16]. Though Maxwell only took into account the particle volume fraction and conductivities of the particle-fluid, hundreds of analytical and empirical models (for example, Equation (2)) later showed [17,18] how multiple factors influence effective thermal conductivity [19].

$$
k_{n}=f\left(\varnothing, k_{f}, k_{p}, v_{B r}, c p_{f}, d_{r e f}, d_{p}, T, v_{f}, T_{b}\right)
$$

where $k_{n}, k_{f}, k_{p}$ are thermal conductivity of nanofluid, base fluid, and particle, respectively. $v_{B r}$ is Brownian velocity, $\mathrm{ms}^{-1} ; c p_{f}$ is specific heat of the base fluid, $\mathrm{Jkg}^{-1} \mathrm{~K}^{-1} ; d_{r e f}$ is reference diameter; $d_{p}$ is diameter of the nanoparticle, $\mathrm{m} ; T$ is temperature, $\mathrm{K} ; v_{f}$ is kinematic viscosity, $\mathrm{m}^{2} \mathrm{~s}^{-1}$; and $T_{b}$ is boiling point temperature of the base fluid, K. However, almost all reports on nanoPCR have ignored the effect of nanoparticle thermal conductivity while explaining the observed PCR enhancement. Several metal oxides and carbon allotropes have been explored as PCR enhancers, but hexagonal boron nitride $(\mathrm{hBN})$ is yet to be studied. hBN is a stable, non-metallic dielectric ceramic material exhibiting high thermal conductivity and chemically inert, often referred to as white graphene [20]. It can be produced using different synthesis routes [21] and is relatively cheaper than its 2D counterparts. Similar to many existing reports on various nanofluids, the thermal conductivity of base fluid increases with the increase in the concentration of hBN nanoparticles [22]. It has been shown that $0.1 \mathrm{wt} \% \mathrm{hBN}$ added to metal stamping lubricant yields over 30\% improvement in thermal conductivity [23]. hBN also shows temperature-dependent thermal conductivity, which may be due to the smaller-sized particles undergoing Brownian motion enabling higher energy transport between particles [24]. Therefore, in this research, the objective is to incorporate $\mathrm{hBN}$ nanoparticles of an optimum concentration into PCR assays owing to their relatively high thermal conductivity, chemically stable properties, and low cost. Since it can enhance Acanthamoeba DNA yield in PCR and improve the efficiency of PCR parameters (e.g., temperature, step, and cycle), it may aid in the rapid detection of Acanthamoeba.

\section{Materials and Methods}

\section{1. hBN Nanoparticle Characterization}

The Raman spectra were studied using the Horiba LabRAM HR Evolution Raman spectrometer (Horiba, Kyoto, Japan). The high angle powder X-ray diffraction patterns (XRD) of the hBN were recorded on a Bruker D8 Discover diffractometer with primary monochromatic high-intensity CuK $\alpha$ radiation $(\lambda=0.15406 \mathrm{~nm})$. The surface structure and elemental composition of the materials were characterized using a field emission scanning electron microscope (FESEM), Hitachi SU8010 (Hitachi, Tokyo, Japan).

\subsection{Acanthamoeba castellanii Cell Cultures}

This study used Acanthamoeba castellanii clinical isolate of T4 genotype and was purchased from American Type Culture Collection (ATCC 50492). It was cultured without shaking in $10 \mathrm{~mL}$ of proteose peptone yeast extract glucose (PYG) growth medium (proteose peptone $0.75 \%(\mathrm{w} / \mathrm{v})$, yeast extract $0.75 \%(\mathrm{w} / \mathrm{v})$, and glucose $1.5 \%(\mathrm{w} / \mathrm{v})$ in a T-75 tissue culture flask at $30{ }^{\circ} \mathrm{C}$ incubator [25]. The growth media was replaced $17-20 \mathrm{~h}$ before the ensuing experiment that obtained $95 \%$ greater A. castellanii trophozoites [26].

\subsection{Acanthamoeba DNA Extraction Using Chelex, Proteinase K, and Genet Bio Kit Methods}

A. castellanii cell pellet was maintained in the trophozoite stage in tissue culture flasks in proteose peptone yeast extract glucose (PYG) growth medium. Upon confluene, the flask was chilled on ice for $20 \mathrm{~min}$ and unbound Acanthamoeba was centrifuged at $2500 \times \mathrm{g}$ for $10 \mathrm{~min}$. The cell pellet was resuspended in $1 \mathrm{~mL}$ of fresh proteose peptone yeast extract glucose (PYG) growth medium, and Acanthamoeba cell counting was determined by using a hemocytometer in volumes containing $1000,5000,10,000,20,000$, and 100,000 cells placed in $1.5 \mathrm{~mL}$ Eppendorf tubes. To the above cell number 
counts, two different methods of DNA extraction were performed, which are $50 \mu \mathrm{L}$ of chelex (Insta-gene matrix, Bio-Rad, Hercules, CA, USA) and $50 \mu \mathrm{L}$ of $20 \mathrm{mg} / \mathrm{mL}$ of proteinase K enzyme (GeNet Bio, Daejeon, South Korea). In both Chelex and Proteinase K DNA extraction methods, the tubes were incubated at $56^{\circ} \mathrm{C}, 95^{\circ} \mathrm{C}, 56^{\circ} \mathrm{C}$, and $100^{\circ} \mathrm{C}$ for $45,10,60$, and $10 \mathrm{~min}$, respectively. Finally, the reaction mixtures of both Chelex and Proteinase K enzyme DNA extraction methods were centrifuged at $2000 \times g$ for $5 \mathrm{~min}$, and the supernatant containing DNA was used as a template in conventional PCR and then analysed for the presence of $A$. castellanii. DNA band, as described previously [27]. The third DNA extraction method was also performed to the above-stated cell number counts, using the GeNet Bio Kit method based on the manufacturer's protocol [28]. For Chelex, Proteinase K, and GeNet Bio Kit DNA extraction methods, nano dropping of the supernatant containing the A. castellanii DNA was measured for DNA concentrations. The Chelex method with A. castellanii cell counts of 1000, 5000, $10,000,20,000$, and 100,000 showed DNA concentrations of 22.51, 110.51, 11.67, 40.82, and $151.9 \mu \mathrm{g} / \mathrm{mL}$, respectively. Their respective DNA purity values were 2.14, 1.72, 4.37, 2.06, and 1.85 A260/280. Next, DNA was diluted to a final volume of $20-50 \mu \mathrm{L}$ to obtain the DNA concentration of $10 \mathrm{ng} / \mu \mathrm{L}$. Proteinase $\mathrm{K}$ method extracted DNA was not diluted because nano dropping showed no DNA concentrations present. Phosphate-buffered saline (PBS) was added to make it to a final volume of $500 \mu \mathrm{L}$ as described previously [27]. GeNet Bio Kit method for the above stated cell count numbers obtained less DNA volume compared to Chelex and proteinase $\mathrm{K}$ methods with DNA concentrations of approximately $13.77-14.21 \mu \mathrm{g} / \mathrm{mL}$ with DNA purity value of approximately $2.80 \mathrm{~A} 260 / 280$.

\subsection{Preparation of hBN Nanofluid}

$\mathrm{hBN}$ nanoparticles of $\sim 70 \mathrm{~nm}$ were dispersed in autoclaved double distilled water to prepare a solution of $10 \mathrm{mM}$ final concentration. For proper mixing of hBN nanoparticles in water, sonication was performed for six hours using a bath-sonicator equipment $(50-60 \mathrm{~Hz}, 50 \mathrm{~W} ; 230 \mathrm{~V}$; ultrasonic bath XUBA1 Grant Ltd.). This well dispersed $\mathrm{hBN}$ nanofluid was used as a stock solution to appropriately dilute a range of various $\mathrm{hBN}$ concentrations $\left(0.4-1 \times 10^{-8} \mathrm{wt} \% \mathrm{hBN}\right)$ similar to our previous report [29]. The thermal conductivity of the samples was measured using a KD2 pro conductivity meter identical to the methodology used in our earlier studies [30].

\subsection{PCR, Nano-PCR, and Gel Electrophoresis}

For Acanthamoeba, PCR was performed in $25 \mu \mathrm{L}$ of the total volume containing $1 \mu \mathrm{L}$ of 1 Unit Prime DNA Taq polymerase (Genet Bio), $1 \mu \mathrm{L}$ of $10 \mathrm{ng} / \mu \mathrm{L}$. DNA, $1 \mu \mathrm{L}$ of $2 \mathrm{mM}$ dNTPs mixture, $8.5 \mu \mathrm{L}$ of nuclease-free water, $1 \mu \mathrm{L}$ of $25 \mu \mathrm{M} \mathrm{MgCl}_{2}$, and $1 \mu \mathrm{L}$ of each $10 \mu \mathrm{M}$ forward and reverse Acanthamoeba genus-specific primer sequences (Table 1) [31]. PCR thermocycler reaction involved initial denaturation at $94{ }^{\circ} \mathrm{C}$ for $3 \mathrm{~min}$ followed by 40 cycles of denaturation at $94{ }^{\circ} \mathrm{C}$ for $30 \mathrm{~s}$, annealing at $50^{\circ} \mathrm{C}$ for $30 \mathrm{~s}$, extension at $72{ }^{\circ} \mathrm{C}$ for $30 \mathrm{~s}$, and a final extension at $72{ }^{\circ} \mathrm{C}$ for $10 \mathrm{~min}$ with an expected PCR amplified product size of $950 \mathrm{bp}$ for $A$. castellanii [28]. PCR assay was repeated 3 times to observe the consistency of visible band strength.

Table 1. Oligonucleotide primers used for Acanthamoeba PCR amplification.

\begin{tabular}{ccccc}
\hline Protist & Gene-Specific Primers & Primer Properties & Amplicon & Reference \\
\hline & Forward primer & Tm: $55.1^{\circ} \mathrm{C}$ & & \\
& $5^{\prime}$-TTTGAATTCGCTCCA & GC content: $31 \%$ & & (Kong and \\
Acanthamoeba & ATAGCGTATATTAA-3' & & $950 \mathrm{bp}$ & Chung, 1996) \\
& Reverse primer & & & [31] \\
& $5^{\prime}$-TTTGAATTCAGAAA & Tm: $55.1^{\circ} \mathrm{C}$ & & \\
& GAGCTATCAATCTGT-3 & GC content: $31 \%$ & & \\
\hline
\end{tabular}

For nano-PCR, hBN nanoparticles were added into PCR reactions to enhance the amplification of T4 genotype DNA using various hBN concentrations $\left(0.4-1 \times 10^{-8}\right.$ wt $\left.\% \mathrm{hBN}\right)$. To determine optimum 
hBN concentration, nano-PCR involved PCR protocol parameters, as described previously [28]. Next, to improve PCR efficiency in the rapid detection of Acanthamoeba, nano-PCR used hBN optimum concentration to test the effects of PCR parameters (e.g., temperature, step, and cycle). Hence, we reduced temperatures in denaturation, annealing, and extension over a range of $5{ }^{\circ} \mathrm{C}$ each, while keeping the step and cycle time constant as previous [28]. Furthermore, using the same optimum $\mathrm{hBN}$ concentration, we reduced the nano-PCR step time of denaturation, annealing, and extension by five seconds each, while keeping temperature and cycle constant as previous [28]. Next, we reduced the number of cycles up to 29 times from previously stated 40 times to reduce time in Acanthamoeba detection. After PCR and nano-PCR, $5 \mu \mathrm{L}$ of equal PCR products were electrophoresed along with a reference DNA ladder of $1 \mathrm{kB}$ (GeneDireX ${ }^{\circledR}$, Bio-Helix Co, Ltd.) on $1 \%$ agarose gels with $1 \times$ TAE buffer and stained with ethidium bromide. Gel electrophoresis of PCR products ran at $100 \mathrm{~V}$ for $45 \mathrm{~min}$. PCR products were visualized under UV illumination [32].

\subsection{Quantitative Analysis of Amplified Nano-PCR Products}

The amounts of amplified PCR products were quantified using NIH Image J software to measure the band density by scanning the gel pictures generated. The band intensities were expressed as arbitrary units (a.u.). Error bars were included using the function "standard error" in the Excel spreadsheet.

\section{Results}

\subsection{Nanoparticle Characterization}

Figure $1 \mathrm{~A}$ shows the XRD pattern of the $\mathrm{hBN}$ nanoparticle used in this work. The peak originating from $\mathrm{hBN}$ were observed at $2 \theta$ angles of $26.8^{\circ}$, and the nanoparticles display high crystallinity owing to its narrow peak. The observed peak can be indexed to (002) of hBN Joint Committee on Powder Diffraction Standard (JCPDS) No.34-0421. The sample was further confirmed using Raman spectra (Figure 1B), which shows a sharp peak at $1363 \mathrm{~cm}^{-1}$. This indicates good quality of hBN used in this study involving the vibration mode of its intralayer $\mathrm{E}_{2 \mathrm{~g}}$. The FESEM image of hBN shown in Figure $1 \mathrm{C}$ shows heterogeneity of its flake size. The flakes are distributed within the range of approximately $50 \mathrm{~nm}$ to 1 micron. The flakes do not look agglomerated and could be easily dispersed in base fluid with the help of sonication.

\subsection{Thermal Conductivity}

Convective heat transfer is a function of the thermal conductivity of the fluid. The thermal conductivity measurements on nanofluids have shown that the conductivity is inversely proportional to the size of the nanoparticle. Other possible reasons for enhanced thermal conductivity include Brownian motion of particles, molecular level layering at the liquid-particle interface, the formation of percolation network, and nanoparticle clustering [15]. Figure 2 shows the thermal conductivity of $\mathrm{hBN}$ nanofluids with respect to increasing temperature at all the concentrations used in this study. Results indicate that the thermal conductivity of the samples is a vital function of particle concentration and temperature. The highest enhancement in thermal conductivity was $141.9 \mathrm{~W} / \mathrm{mk}$ with $0.2 \mathrm{wt} \%$ $\mathrm{hBN}$. High thermal conductivity could also be attributed to the highly crystalline nature of the hBN powder used in this study, which might induce longer phonon scattering mean free path [33]. Further increase in the concentration may not help since agglomeration would result in sedimentation affecting the thermal conductivity unless the particles are functionalized [34]. It is also proposed that the higher concentration leads to nanoparticle populated network, which is not as efficient as the co-existence of dynamic free particles and local clusters, which could lead to lower conductivity at higher temperatures. Moreover, the higher concentration would also contribute to the increase in heat capacity of the reaction, which may affect the yield and reaction fidelity. 

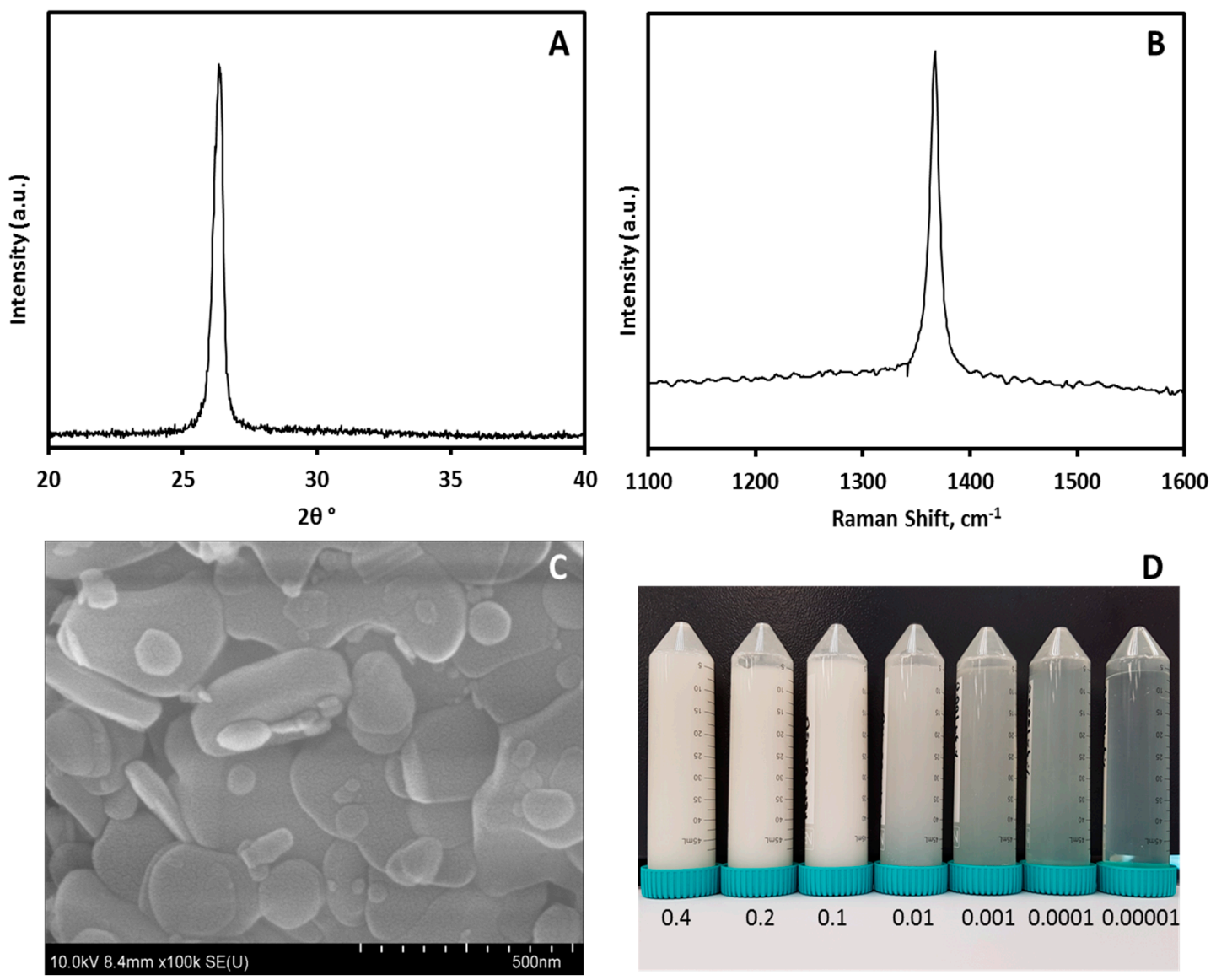

Figure 1. (A) Powder X-ray diffraction (XRD) on hBN nanoparticles at atmospheric pressure. (B) Raman Spectra of hBN nanoparticles. (C) Field Emission Scanning Electron Microscopic (FESEM) image of hBN measured at $10 \mathrm{kV}$ vacuum condition. (D) Serially diluted samples of $\mathrm{hBN}-\mathrm{ddH}_{2} \mathrm{O}$ from a stock of $0.4 \mathrm{wt} \%$.

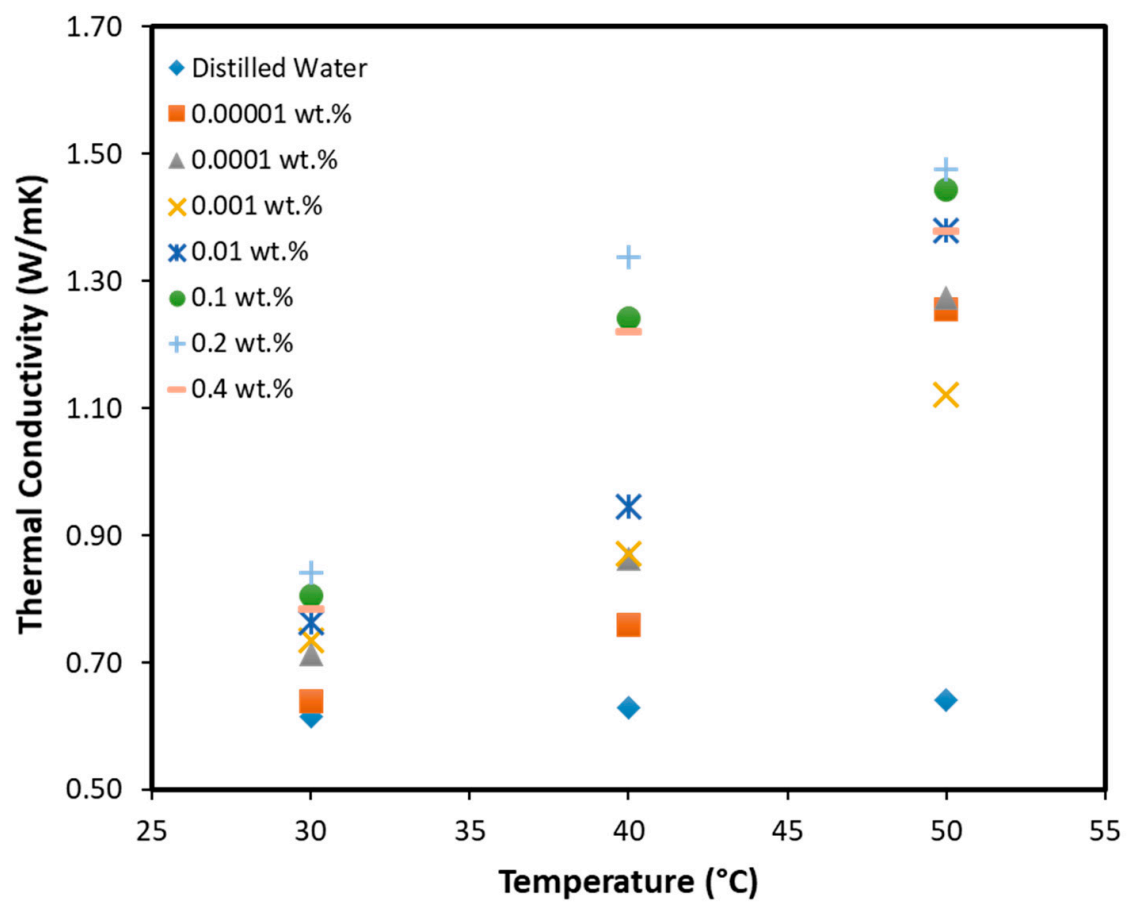

Figure 2. Thermal conductivity measured at three different temperatures of dd- $\mathrm{H} 2 \mathrm{O}$ and a range of hBN-ddH2O concentration. 
3.3. Chelex Assay with 10,000 Acanthamoeba Cells Was Optimized among Three DNA Extraction Methods Tested to Identify Low Cell Numbers

Acanthamoeba T4 genotype DNA were observed for PCR bands in various cell numbers of 1000, 5000, 10,000, 20,000, and 100,000, which obtained the expected $950 \mathrm{bp}$ amplicon (Figure 3A-C). For clinical purposes, a sensitive detection assay is essential to identify Acanthamoeba at low cell numbers. Chelex assay consistently obtained sharp, bright PCR bands under 20,000 cells as no DNA loss occurs via washing steps (Figure 3A). Proteinase K assay showed PCR bands in $>5000$ cells with low DNA yield implicating low fidelity of this enzyme due to heat inactivated degradation (Figure 3B). GeNet Bio Kit assay showed bright PCR bands for $>10,000$ cells, but PCR band was absent at lower 5000 cells indicating loss of DNA caught on the filter during the washing process (Figure 3C). No band was present for the negative control, hence no contamination occurred. Note chelex assay with 10,000 A. castellanii cells in $10 \mathrm{ng} / \mu \mathrm{L}$. concentration was selected as optimum (Figure 3A).

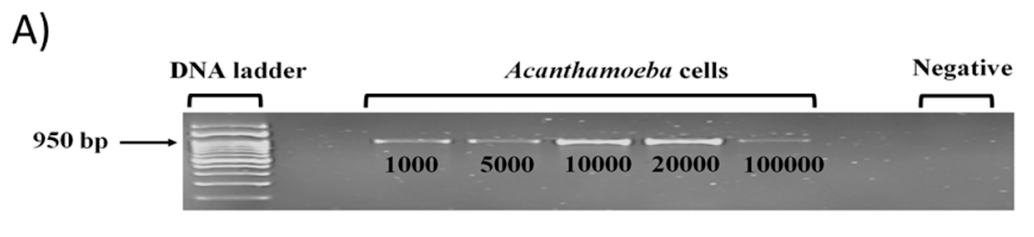

B)

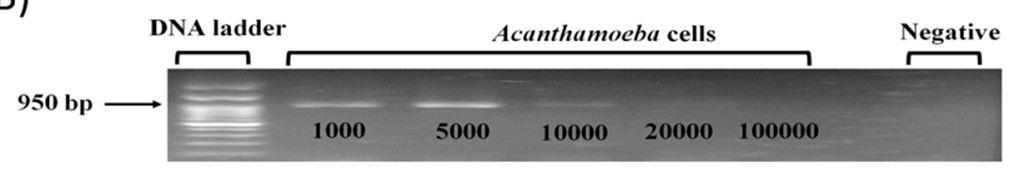

C)

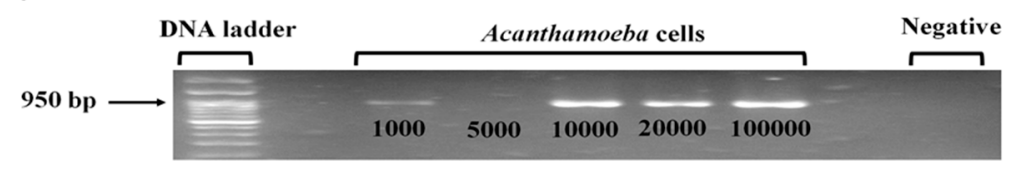

Figure 3. Agarose gel image showing PCR amplification of $18 \mathrm{~S} \mathrm{rDNA}$ of $A$. castellanii of the T4 genotype using three different DNA extraction methods, (A) Chelex assay, (B) Proteinase K assay, and (C) GeNet Bio Kit assay.

\subsection{HBN Nanoparticle Enhances Acanthamoeba Detection in PCR and Increases PCR DNA Yield}

hBN nanoparticles with a concentration of $0.4-1 \times 10^{-8} \mathrm{wt} \%$ were added to the PCR reaction mixture containing 10,000 A. castellanii cells to test the effects of hBN on Acanthamoeba detection. Gel image results revealed that $1 \times 10^{-4}$ wt $\% \mathrm{hBN}$ optimum nanoparticle concentration enhanced Acanthamoeba PCR DNA yield (Figure 4A). ImageJ software showed that $1 \times 10^{-4} \mathrm{wt} \% \mathrm{hBN}$ optimum nanoparticle concentration resulted in a 1.16-fold increase in band density (Figure 4B). Out of the eight trials carried out to establish the optimal concentration, most of the bands indicated to $1 \times 10^{-4}$ $\mathrm{wt} \% \mathrm{hBN}$ as the optimal concentration. However, possibly due to human error while loading PCR product in the agarose gel, a perfect bell pattern could not be achieved in the graph based on image intensity quantification. The best gel image is presented in (Figure $4 \mathrm{~A}$ ) as a representation of the effect of nanoparticle concentration. 
A)

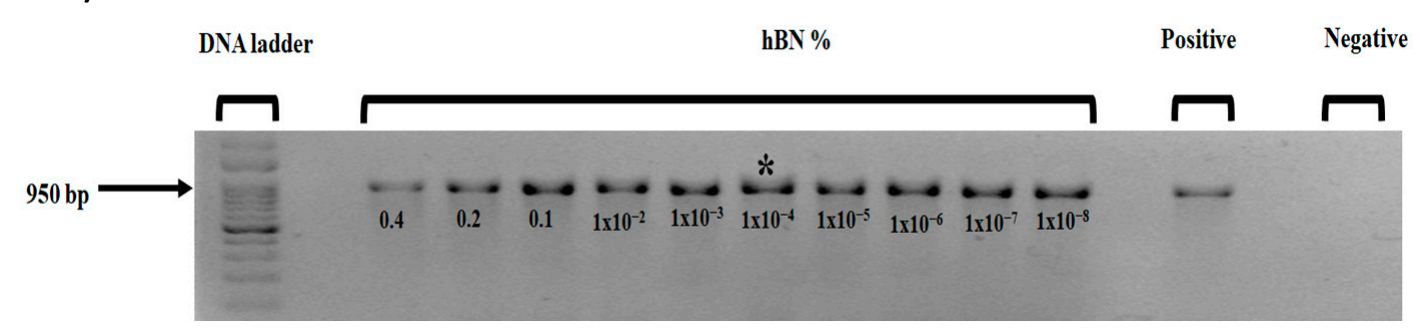

B)

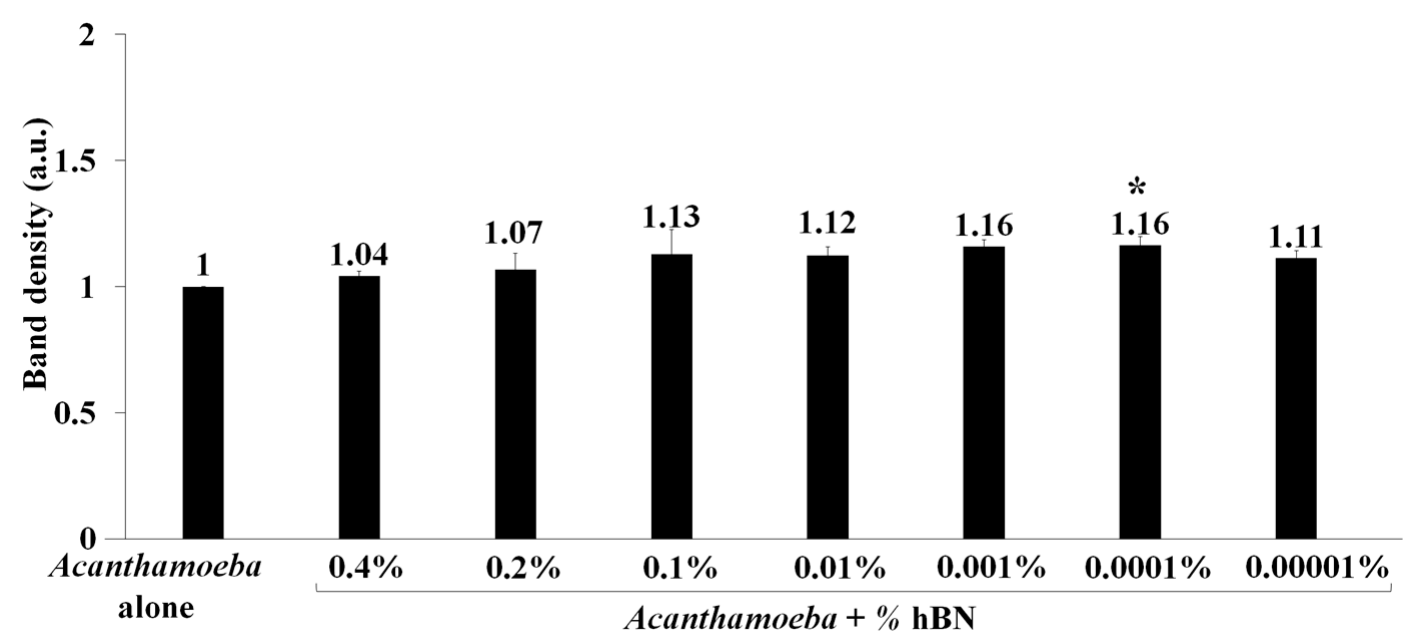

Figure 4. (A) Agarose gel image showing concentration-dependent hBN nanoparticles effects on PCR amplification of $A$. castellanii. Lane "hBN \%" indicates $0.4-1 \times 10^{-8} \mathrm{wt} \% \mathrm{hBN}$ nanoparticle concentration in PCR along with 10,000 A. castellanii cells enhanced PCR products in gradual increments of DNA yield. An expected amplicon size of $950 \mathrm{bp}$ was obtained. Lane positive control indicates PCR reaction with a DNA template but without hBN nanoparticles. Lane negative control indicates PCR reaction with distilled water but without added DNA template and hBN nanoparticles. (B) Quantitative graph of $950 \mathrm{bp}$ Acanthamoeba PCR band density in the presence of $\left(0.4-1 \times 10^{-8} \mathrm{wt} \%\right) \mathrm{hBN}$ nanoparticles against the absence of hBN nanoparticles. The PCR amplicon in the absence of nanoparticles was considered as 1 arbitrary unit (a.u.) compared to amplicons in the presence of hBN nanoparticles as relative amounts of PCR yield increase. Note hBN nanoparticles improved Acanthamoeba PCR yield by $\sim 16 \%$ at maximum optimum concentration of $1 \times 10^{-4} \mathrm{wt} \%$ indicated in both $(\mathbf{A})$ and $(\mathbf{B})$ with $\left(^{*}\right)$.

\section{5. hBN Nanoparticle Reduces PCR Temperature to Enhance Acanthamoeba Detection and} Increases DNA Yield

To test the effects of hBN nanoparticle on Acanthamoeba detection at reduced PCR temperatures for denaturation, annealing, and extension an optimum nanoparticle concentration was added to PCR reaction mixture containing 10,000 A. castellanii cells. Gel image results revealed $1 \times 10^{-4} \mathrm{wt} \% \mathrm{hBN}$ optimum nanoparticle concentration enhanced Acanthamoeba PCR DNA yield at $46.2^{\circ} \mathrm{C}$ low annealing temperature as primers effectively hybridized to target gene; followed by low denaturation and extension temperatures at $91.5^{\circ} \mathrm{C}$ and $68^{\circ} \mathrm{C}$, respectively. However, at this same annealing temperature, no DNA amplification occurred for Acanthamoeba positive control without hBN nanoparticle (Figure 5A). Quantification of band density in gel images showed that $1 \times 10^{-4} \mathrm{wt} \% \mathrm{hBN}$ optimum nanoparticle concentration resulted in $\sim 2.0$-fold increase in band density at $46.2{ }^{\circ} \mathrm{C}$ low annealing temperature (Figure 5B). 
A)

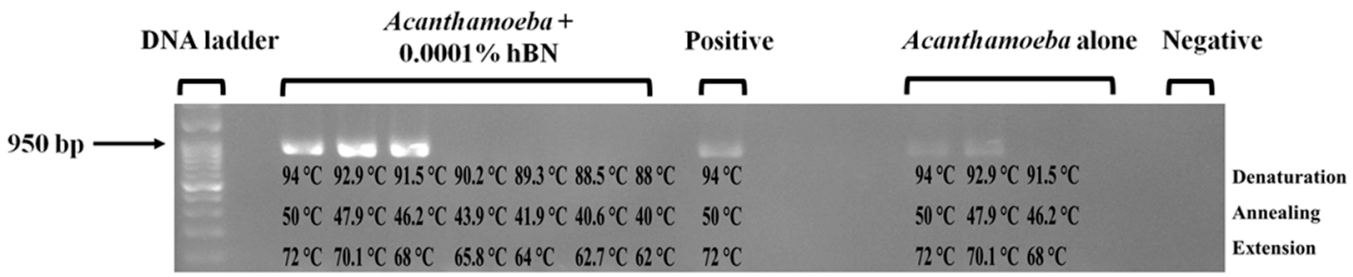

B)

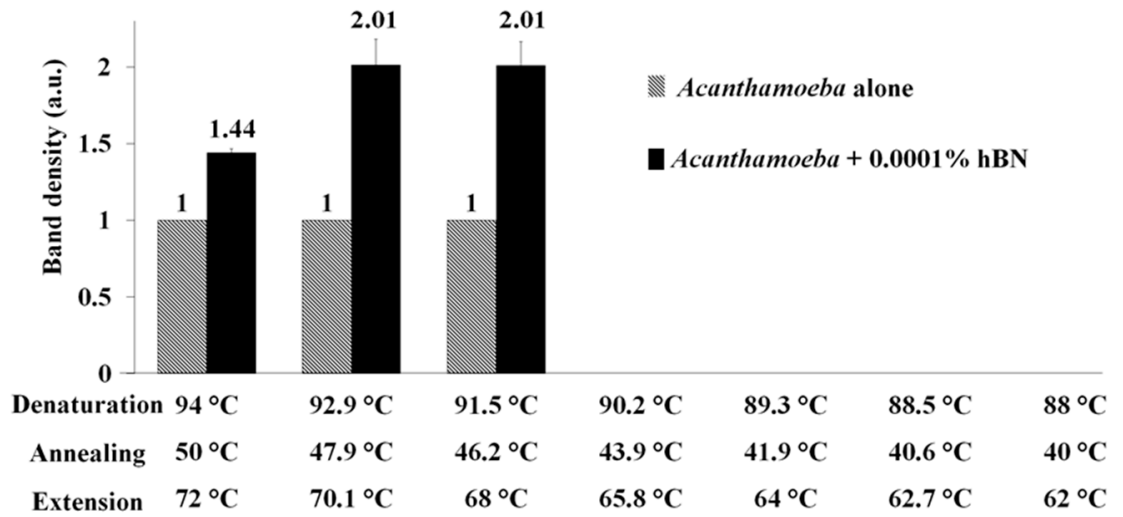

Figure 5. (A) Agarose gel image showing a range of reduced temperature-dependent effects on PCR amplification of $A$. castellanii. Lane "Acanthamoeba $+0.0001 \% \mathrm{hBN}$ " indicates $1 \times 10^{-4} \mathrm{wt} \%$ optimum hBN concentration along with 10,000 A. castellanii enhanced Acanthamoeba PCR products in gradual increments of DNA yield at reduced PCR temperatures for denaturation, annealing, and extension. An expected amplicon size of $950 \mathrm{bp}$ was obtained. Lane positive control and "Acanthamoeba alone" indicates PCR reaction with DNA template but without hBN nanoparticle. Lane negative control indicates PCR reaction with distilled water but without added DNA template and hBN nanoparticle. (B) Quantitative graph of $950 \mathrm{bp}$ Acanthamoeba PCR band density in the presence of hBN nanoparticle against the absence of hBN nanoparticles at reduced PCR temperatures for denaturation, annealing and extension. The PCR amplicon in the absence of nanoparticles was measured as 1 arbitrary unit (a.u.) compared to amplicons in presence of hBN nanoparticles as relative amounts of PCR yield increase. Note $1 \times 10^{-4}$ wt \% optimum hBN nanoparticle concentration improved Acanthamoeba PCR yield by $\sim 100 \%$ at lowest $46.2^{\circ} \mathrm{C}$ annealing temperature.

\section{6. hBN Nanoparticle Reduces PCR Step Time to Enhance Acanthamoeba Detection}

To test the effects of hBN nanoparticle on Acanthamoeba detection at reduced PCR step time for denaturation, annealing, and extension an optimum nanoparticle concentration was added to PCR reaction mixture containing 10,000 A. castellanii cells. Gel image results revealed that reduction in PCR step time from 30 to $25 \mathrm{~s}$ using $1 \times 10^{-4} \mathrm{wt} \% \mathrm{hBN}$ optimum nanoparticle concentration did not cause any decrease in the amount of amplified PCR product compared to the Acanthamoeba positive control without hBN nanoparticle (Figure 6A). Quantification of band density in gel images showed that $1 \times 10^{-4}$ wt $\%$ hBN optimum nanoparticle concentration resulted in partial improvement of Acanthamoeba DNA yield at $25 \mathrm{~s}$ (Figure 6B). 
A)

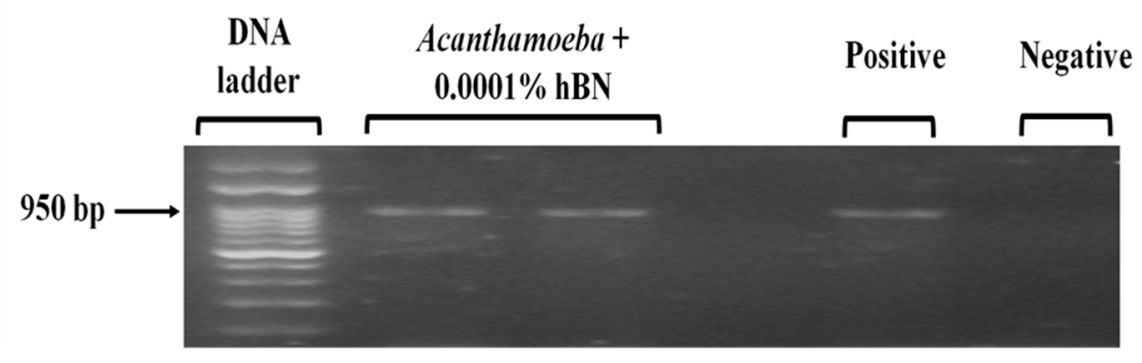

B)

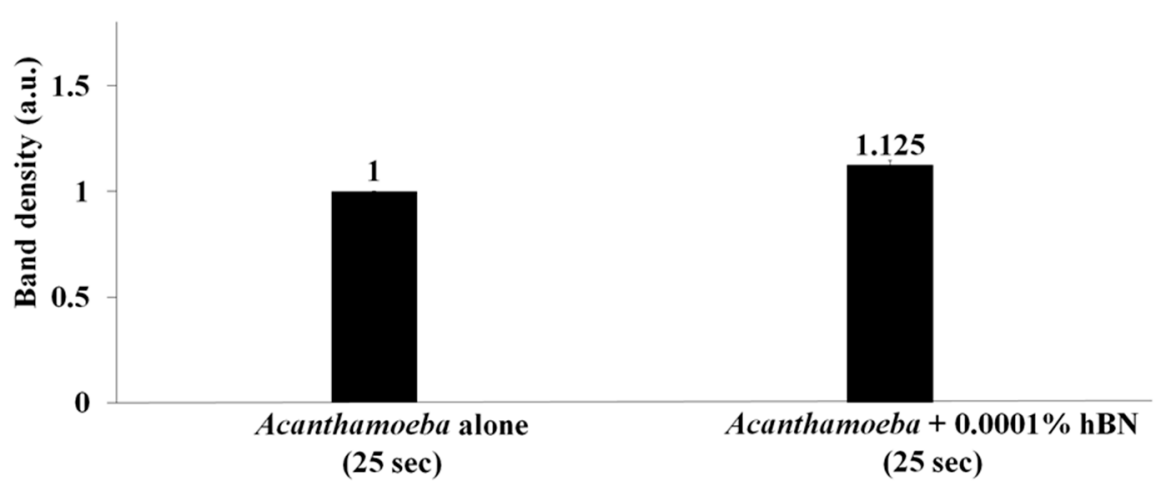

Figure 6. (A) Agarose gel image showing effects of reduced PCR step time on PCR amplification of A. castellanii. Lane "Acanthamoeba $+0.0001 \% \mathrm{hBN}$ " indicates $1 \times 10^{-4} \mathrm{wt} \%$ optimum hBN concentration along with 10,000 A. castellanii cells did not cause any decrease in the amount of amplified Acanthamoeba PCR products at reduced PCR step time from 30 to $25 \mathrm{~s}$ for denaturation, annealing, and extension. An expected amplicon size of 950 bp was obtained. Lane "Acanthamoeba alone" indicates PCR reaction with DNA template but without hBN nanoparticle. Lane negative control indicates PCR reaction with distilled water but without added DNA template and hBN nanoparticle. (B) Quantitative graph of $950 \mathrm{bp}$ Acanthamoeba PCR band density in the presence of hBN nanoparticles against the absence of hBN nanoparticles at reduced PCR step time for denaturation, annealing, and extension. The PCR amplicon in the absence of nanoparticles was measured as 1 arbitrary unit (a.u.) compared to amplicons in the presence of hBN nanoparticles as relative amounts of PCR yield increase. An optimum hBN nanoparticle concentration of $1 \times 10^{-4} \mathrm{wt} \%$ partially improved Acanthamoeba DNA yield at $25 \mathrm{~s}$.

\section{7. hBN Nanoparticle Reduces PCR Cycle Time to Enhance Acanthamoeba Detection}

To test the effects of hBN nanoparticle on Acanthamoeba detection at reduced PCR cycle time an optimum nanoparticle concentration was added to PCR reaction mixture containing 10,000 A. castellanii cells. Gel image results revealed that reduction in PCR cycle number from $40 \times$ to $29 \times$ using $1 \times 10^{-4}$ wt $\%$ hBN optimum nanoparticle concentration did not cause any decrease in the amount of amplified PCR product compared to the Acanthamoeba positive control without hBN nanoparticles, suggesting that hBN nanoparticles can rapidly reduce overall PCR cycle number by $11 \times$ and time by 32 min; thus, enhancing Acanthamoeba detection (Figure 7A). Quantification of band density in gel images showed that $1 \times 10^{-4}$ wt $\% \mathrm{hBN}$ optimum nanoparticle concentration partially improved Acanthamoeba DNA yield at 29 cycles (Figure 7B). 
A)

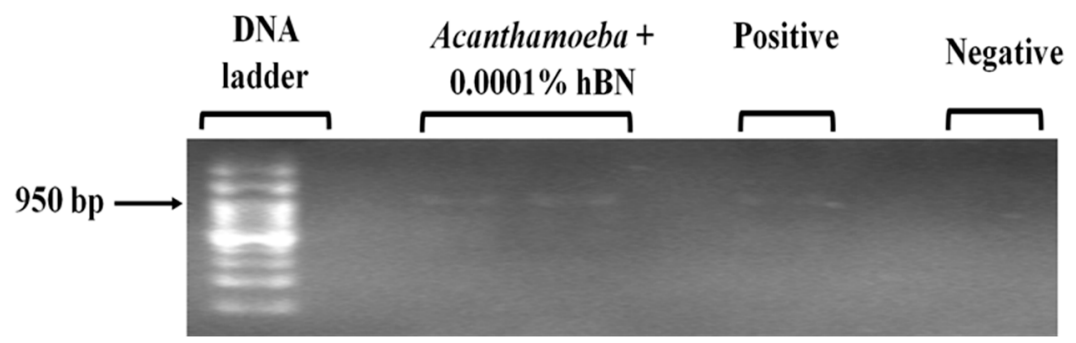

B)

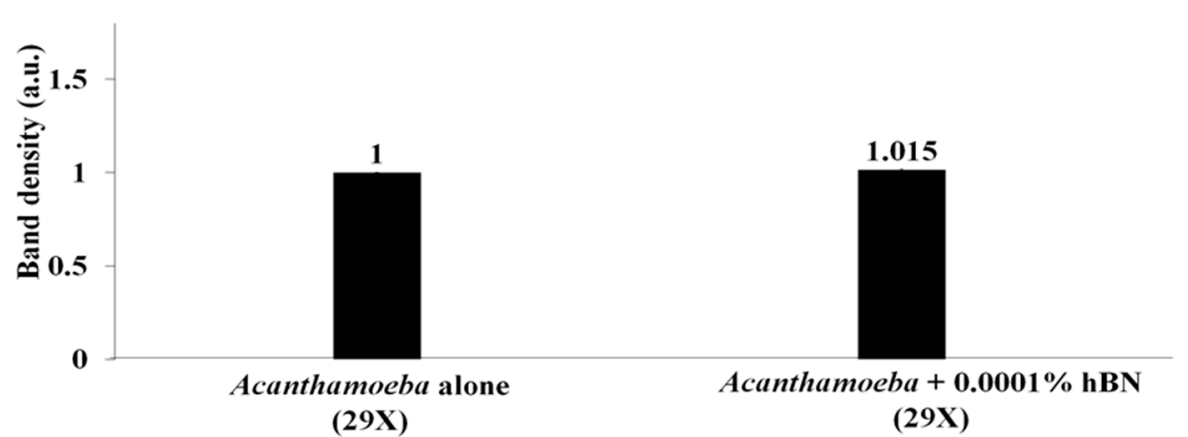

Figure 7. (A) Agarose gel image showing effects of reduced PCR cycle time on PCR amplification of A. castellanii. Lane "Acanthamoeba $+0.0001 \% \mathrm{hBN}$ " indicates $1 \times 10^{-4} \mathrm{wt} \%$ optimum hBN concentration along with 10,000 A. castellanii cells did not cause any decrease in the amount of amplified Acanthamoeba PCR products at reduced PCR cycle number from $40 \times$ to $29 \times$ for denaturation, annealing, and extension. An expected amplicon size of 950 bp was obtained. Lane "Acanthamoeba alone" indicates PCR reaction with DNA template but without hBN nanoparticle. Lane negative control indicates PCR reaction with distilled water but without added DNA template and hBN nanoparticle. (B) Quantitative graph of $950 \mathrm{bp}$ Acanthamoeba PCR band density in the presence of hBN nanoparticles against the absence of hBN nanoparticles at reduced PCR cycles from $40 \times$ to $29 \times$. The PCR amplicon in the absence of nanoparticles was measured as 1 arbitrary unit (a.u.) compared to amplicons in presence of hBN nanoparticles as relative amounts of PCR yield increase. An optimum hBN nanoparticle concentration of $1 \times 10^{-4}$ wt \% partially improved Acanthamoeba DNA yield at $29 \times$.

\section{Discussion}

In most clinical cases, detection of the Acanthamoeba T4 genotype prevalent in $94 \%$ Acanthamoeba keratitis eye infection cases is delayed because bacterial, viral, and fungal keratitis are primarily tested [6]. For example, lethal ring infiltrate developed in Acanthamoeba keratitis patient due to treatment initiated for bacterial keratitis. Hence, a highly sensitive detection method is required to isolate Acanthamoeba from low amoeba cell density to prevent exacerbation of disease symptoms. Currently, PCR assay is used in Acanthamoeba detection. However, insufficient DNA yield [1] and reduced PCR specificity in Acanthamoeba DNA amplification suggests that non-specific amplification remains an issue [8]. Note, chelex assay with 10,000 A. castellanii cells in $10 \mathrm{ng} / \mu \mathrm{L}$ concentration was selected as the optimum cell count number to react with $\mathrm{hBN}$ in the PCR reaction mixture. GeNet Bio Kit assay showed the presence of bright PCR bands for samples; however, the PCR band was absent at lower 5000 cells indicating loss of DNA, which was perhaps caught on the filter during the washing process. Chelex assay consistently obtained sharp, bright PCR bands for all the samples, which means no DNA loss occurred because there were no washing steps involved like the GeNet Bio Kit assay. Chelex involves fewer steps to extract the DNA, which makes it less prone to errors in losing the DNA compared to GeNet Bio Kit method. 
In particular, nanoparticles have been developed as a PCR enhancer to improve PCR efficiency. Many nanoparticles have been developed to enhance PCR specificity and improve PCR DNA yield, such as $\mathrm{TiO}_{2}$, gold, and graphene [10]. As hBN is firstly cheaper, present in higher abundance, inert (does not oxidize in air up to $900{ }^{\circ} \mathrm{C}$ ) and is highly resistant to chemical attacks, it exhibits weak interaction with other chemical substances (i.e., metabolites or phenolic compounds) present in amoeba samples from clinics and environment; thus, it is a nanoparticle of choice to improve Acanthamoeba PCR amplification. Interestingly, in our study, $70 \mathrm{~nm} \mathrm{hBN} \mathrm{nanoparticles} \mathrm{of} \mathrm{as} \mathrm{low} \mathrm{optimum} \mathrm{concentration}$ of $1 \times 10^{-4} \mathrm{wt} \%$ showed enhanced PCR yield by $\sim 16 \%$ for 10,000 Acanthamoeba cells (Figure $4 \mathrm{~B}$ ). This observation is comparable to the enhanced DNA yield of Acanthamoeba in PCR assay using graphene, copper, and alumina nanoparticles, as reported in our previous study [28]. Given the high surface area to volume ratio of $70 \mathrm{~nm} \mathrm{hBN}$ nanoparticles, it provides greater surface availability for adsorption and desorption of small primers, DNA template, and DNA polymerase enzyme with enhanced reactivity nanomaterial surface [7]. Thus, the high surface area property of hBN nanoparticles is advantageous to generate a greater number of PCR amplicons with a low amount of $(10 \mathrm{ng} / \mu \mathrm{L}$.) template concentration compared to amoeba positive control without nanoparticle (Figure 4A) that improves PCR efficiency in Acanthamoeba detection.

Nanoparticles have high thermal conductivity to enhance PCR specificity and DNA yield [7]. hBN nanoparticle is thermally stable with high thermal conductivity theoretical value of $600-1000 \mathrm{~W} \mathrm{~m}^{-1} \mathrm{~K}^{-1}$ [13]. Interestingly, in our study, hBN nanoparticle of $1 \times 10^{-4} \mathrm{wt} \%$ optimum concentration resulted in a $\sim 2$.0-fold increase of Acanthamoeba PCR yield at a low annealing temperature of $46.2^{\circ} \mathrm{C}$ (Figure 5B). This observation is consistent with graphene nanoparticles in the PCR assay, which enhanced human mitochondrial DNA yield at a low annealing temperature of $25^{\circ} \mathrm{C}$ [12]. The low annealing temperature is vital to reduce non-specific amplification and increase PCR specificity because primers must effectively hybridize to target genes and not with any other similar sequences [9]. However, in conventional PCR, a very low annealing temperature is not favourable because non-uniform heat distribution occurs among PCR reagents due to repeated heating and cooling process of PCR thermocycler that may cause non-specific amplification and low DNA yield. Hence, we have observed that hBN nanoparticle showed a bright PCR band at low annealing temperature of $46.2^{\circ} \mathrm{C}$ due to enhanced heat transfer as well as uniform heat distribution to Acanthamoeba primers and DNA template; whereas, no DNA amplification was shown at similar annealing temperature for Acanthamoeba positive control without hBN nanoparticle (Figure $5 \mathrm{~A}$ ). Thus, the heat transfer property of hBN nanoparticle is advantageous to generate a greater number of amplicons and improve PCR efficiency in Acanthamoeba detection. The presence of nanoparticle around the PCR reagents would augment Brownian motion induced heat transfer. In case of agglomerated particles distributed and in contact with individual 2D flakes, they would also create a path for rapid heat transfer.

Reduction of PCR step time from 30 to $25 \mathrm{~s}$ in denaturation, annealing, and extension observed Acanthamoeba PCR bands using $1 \times 10^{-4} \mathrm{wt} \% \mathrm{hBN}$ optimum nanoparticle concentration. There was no observed decrease in the amount of amplified PCR product with hBN compared to Acanthamoeba positive control without hBN nanoparticle, suggesting that overall PCR step time can be reduced by $10 \mathrm{~min}$; thus, enhancing Acanthamoeba detection (Figure 6B). Similarly, 11 cycles were reduced from initial 40× cycles from Figure $4 \mathrm{~B}$ using $1 \times 10^{-4}$ wt $\%$ hBN optimum concentration to $29 \times$ using $1 \times 10^{-4}$ wt \% hBN optimum nanoparticle concentration which saves $32 \mathrm{~min}$ in Acanthamoeba detection time, without any decrease in amplified PCR product compared to positive control (Figure 7B). The clinical diagnosis maybe expedited with a reduction in PCR reaction time. The partial DNA enhancement in both PCR step and cycle reaction may attribute to reduced number of PCR reactions occurring per cycle. Nevertheless, PCR bands were still observed with hBN at a much shorter time indicating that $\mathrm{hBN}$ nanoparticles did not inhibit PCR reaction for low amounts of Acanthamoeba $10 \mathrm{ng} / \mu \mathrm{L}$. template concentration. Interestingly, bare $\mathrm{hBN}$ nanoparticles were reported to be non-cytotoxic to osteoblast bone cells and macrophage cells evaluated for hBN suitability in orthopedic implants [35], suggesting that hBN is likely non-toxic to DNA. 
Although the precise mechanism of action between hBN nanoparticle and PCR reagents requires further study, enhancement of Acanthamoeba PCR DNA yield is possibly due to high adsorption affinity of hBN nanoparticles to purine (Guanine-G) [36], which is favorable to break strong GC rich hydrogen bonds of double stranded DNA template in PCR denaturation step. It was also reported that DNA nucleobases retained stable configurations when hBN nanoparticle surface adsorbed the DNA template [37]. Polar hBN nanoparticles adsorb negatively charged phosphate backbone of primers and DNA templates in the PCR annealing step due to electrostatic interactions, as depicted in the graphical illustration, Figure 8. Desorption of attached nucleic acids occurs when complementary sequences are present, which prevents non-specific amplification, resulting in enhanced PCR specificity. Finally, DNA amplification occurs in the PCR extension step due to a more significant catalytic activity of DNA polymerase enzyme [7]. The entire process of adsorption and desorption of DNA strands over nanoparticles must have also been strongly influenced by the augmented heating-cooling rates due to hBN. The higher thermal conductivity achieved in the PCR mixture due to the addition of hBN could have been a result of Brownian motion of hBN, liquid layering around the flakes, percolation network of hBN flakes and its agglomerates, and thermophoretic effect. Nonetheless, further studies on each mechanism highlighted here are required to establish a factual basis for nanoparticle enhanced PCR reactions.
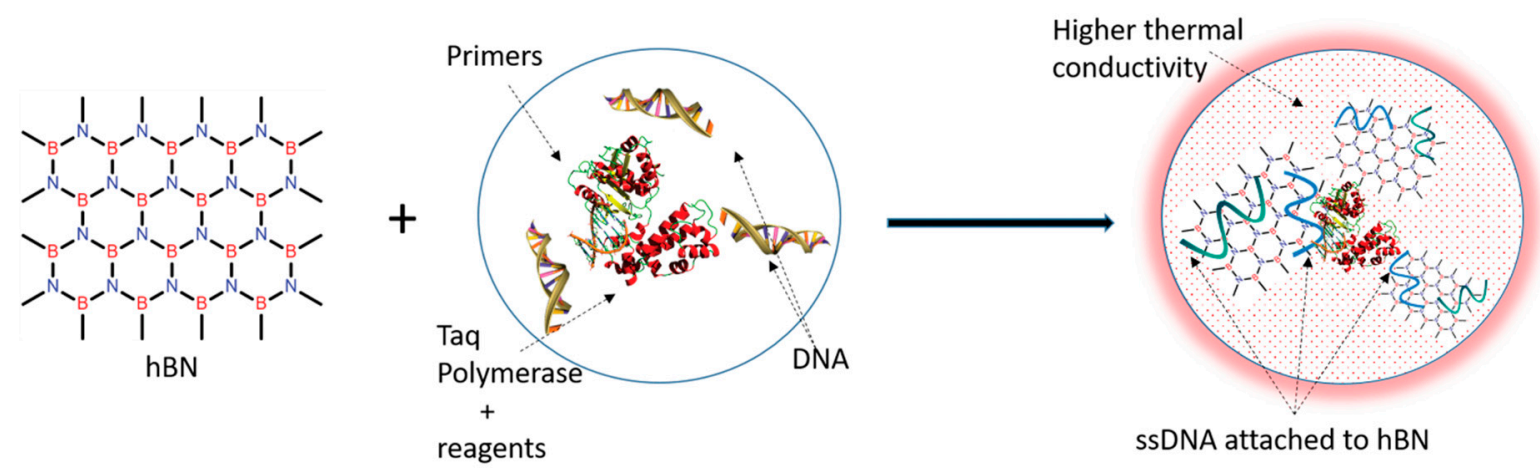

Figure 8. Graphical representation hBN induced enhanced thermal conductivity of PCR.

In conclusion, hexagonal boron nitride ( $\mathrm{hBN}$ ) nanotechnology-based PCR improves PCR DNA yield in Acanthamoeba detection and can be useful for clinical applications or water companies in rapid detection of Acanthamoeba. An optimal concentration of $\mathrm{hBN}, 0.4-1 \times 10^{-8} \mathrm{wt} \%$ increases the DNA yield. The fidelity of PCR with $\mathrm{hBN}$ is a function of its concentration. The addition of $\mathrm{hBN}$ significantly helps in reducing the reaction step time, number of cycles, and temperature without compromising the yield with respect to positive control. Enhanced thermal conductivity induced adsorption and subsequent desorption of DNA over $\mathrm{hBN}$ is proposed to be the underlying mechanism of the enhancements observed in this study. However, it requires further investigation, particularly from the better PCR yield quantification point of view.

Author Contributions: Conceptualization, A.K.R. and N.A.K.; methodology, S.M.K.A.; validation, S.M.K.A., R.S. and S.G.; formal analysis, A.K.R. and S.M.K.A.; investigation, S.M.K.A., M.Z.J., A.J.; resources, N.A.K. and R.S.; data curation, A.K.R., S.G. and S.M.K.A.; writing-original draft preparation, A.K.R., S.M.K.A.; writing一review and editing, N.A.K., R.S., supervision, A.K.R., R.S. and N.A.K.; project administration, M.Z.J. and A.J., A.K.R.; funding acquisition, N.A.K. and R.S. All authors have read and agreed to the published version of the manuscript.

Funding: This work is supported by the American University of Sharjah.

Acknowledgments: The work in this paper was supported, in part, by the Open Access Program from the American University of Sharjah. This paper represents the opinions of the author(s) and does not mean to represent the position or opinions of the American University of Sharjah.

Conflicts of Interest: The authors declare no conflict of interest. 


\section{References}

1. Centers for Disease Control and Prevention. Acanthamoeba Infection FAQs. Available online: https: //www.cdc.gov/parasites/acanthamoeba/gen_info/acanthamoeba.html (accessed on 30 July 2020).

2. Lorenzo-Morales, J.; Khan, N.A.; Walochnik, J. An update on Acanthamoeba keratitis: Diagnosis, pathogenesis and treatment. Parasite 2015, 22, 10. [CrossRef]

3. Boggild, A.K.; Martin, D.S.; Lee, T.Y.; Yu, B.; Low, D.E. Laboratory diagnosis of amoebic keratitis: Comparison of four diagnostic methods for different types of clinical specimens. J. Clin. Microbiol. 2009, 47, 1314-1318. [CrossRef]

4. Hau, S.C.; Dart, J.K.; Vesaluoma, M.; Parmar, D.N.; Claerhout, I.; Bibi, K.; Larkin, D.F. Diagnostic accuracy of microbial keratitis with in vivo scanning laser confocal microscopy. Br. J. Ophthalmol. 2010, 94, 982-987. [CrossRef]

5. Bhosale, N.K.; Parija, S.C.; Mandal, J.; Ahuja, S. Utility of Polymerase chain reaction in diagnosis of Acanthamoeba and Microsporidial keratitis. Int. J. Infect. Dis. 2016, 45, 354. [CrossRef]

6. Visvesvara, G.S.; Moura, H.; Schuster, F.L. Pathogenic and opportunistic free-living amoebae: Acanthamoeba spp., Balamuthia mandrillaris, Naegleria fowleri, and Sappinia diploidea. Pathog. Dis. 2007, 50, 1-26. [CrossRef]

7. Yuce, M.; Kurt, H.; Mokkapati, V.R.S.S.; Budak, H. Employment of nanomaterials in polymerase chain reaction: Insight into the impacts and putative operating mechanisms of nano-additives in PCR. Rsc Adv. 2014, 4, 36800-36814. [CrossRef]

8. Zhao, G.; Zhai, H.; Yuan, Q.; Sun, S.; Liu, T.; Xie, L. Rapid and sensitive diagnosis of fungal keratitis with direct PCR without template DNA extraction. Clin. Microbiol. Infect. 2014, 20, O776-O782. [CrossRef] [PubMed]

9. Lorenz, T.C. Polymerase chain reaction: Basic protocol plus troubleshooting and optimization strategies. J. Vis. Exp. 2012, e3998. [CrossRef] [PubMed]

10. Fu-Ming, S.; Xin, L.; Jia, L. Development of Nano-Polymerase Chain Reaction and Its Application. Chin. J. Anal. Chem. 2017, 45, 1745-1753. [CrossRef]

11. Kim, H.R.; Baek, A.; Lee, I.J.; Kim, D.-E. Facilitation of Polymerase Chain Reaction with Poly (ethylene glycol)-Engrafted Graphene Oxide Analogous to a Single-Stranded-DNA Binding Protein. Acs Appl. Mater. Interfaces 2016, 8, 33521-33528. [CrossRef] [PubMed]

12. Jia, J.; Sun, L.; Hu, N.; Huang, G.; Weng, J. Graphene enhances the specificity of the polymerase chain reaction. Small 2012, 8, 2011-2015. [CrossRef] [PubMed]

13. Wang, N.; Wang, H.; Tang, C.; Lei, S.; Shen, W.; Wang, C.; Wang, G.; Wang, Z.; Wang, L. Toxicity evaluation of boron nitride nanospheres and water-soluble boron nitride in Caenorhabditis elegans. Int. J. Nanomed. 2017, 12, 5941-5957. [CrossRef] [PubMed]

14. Maxwell, J.C. A Treatise on Electricity and Magnetism; Clarendon: Oxford, UK, 1892; Volume 2, pp. 68-73.

15. Keblinski, P.; Phillpot, S.; Choi, S.; Eastman, J. Mechanisms of heat flow in suspensions of nano-sized particles (nanofluids). Int. J. Heat Mass Transfer 2002, 45, 855-863. [CrossRef]

16. Dhar, P.; Gupta, S.S.; Chakraborty, S.; Pattamatta, A.; Das, S.K. The role of percolation and sheet dynamics during heat conduction in poly-dispersed graphene nanofluids. Appl. Phys. Lett. 2013, 102, 163114. [CrossRef]

17. Eastman, J. Novel Thermal Properties of Nanostructured Materials; Argonne National Lab.: Lemont, IL, USA, 1999. Available online: https://www.osti.gov/servlets/purl/10862 (accessed on 23 July 2020).

18. Rasheed, A.K.; Khalid, M.; Rashmi, W.; Gupta, T.C.S.M.; Chan, A. Graphene based nanofluids and nanolubricants—Review of recent developments. Renew. Sustain. Energy Rev. 2016, 63, 346-362. [CrossRef]

19. Hassani, S.; Saidur, R.; Mekhilef, S.; Hepbasli, A. A new correlation for predicting the thermal conductivity of nanofluids; using dimensional analysis. Int. J. Heat Mass Transf. 2015, 90, 121-130. [CrossRef]

20. Ilhan, B.; Kurt, M.; Ertürk, H. Experimental investigation of heat transfer enhancement and viscosity change of hBN nanofluids. Exp. Therm. Fluid Sci. 2016, 77, 272-283. [CrossRef]

21. Qayyum, M.S.; Hayat, H.; Matharu, R.K.; Tabish, T.A.; Edirisinghe, M. Boron nitride nanoscrolls: Structure, synthesis, and applications. Appl. Phys. Rev. 2019, 6, 021310. [CrossRef]

22. Krishnam, M.; Bose, S.; Das, C. Boron nitride (BN) nanofluids as cooling agent in thermal management system (TMS). Appl. Therm. Eng. 2016, 106, 951-958. [CrossRef] 
23. Taha-Tijerina, J.; Peña-Paras, L.; Narayanan, T.N.; Garza, L.; Lapray, C.; Gonzalez, J.; Palacios, E.; Molina, D.; García, A.; Maldonado, D.; et al. Multifunctional nanofluids with 2D nanosheets for thermal and tribological management. Wear 2013, 302, 1241-1248. [CrossRef]

24. Aravind, S.J.; Baskar, P.; Baby, T.T.; Sabareesh, R.K.; Das, S.; Ramaprabhu, S. Investigation of structural stability, dispersion, viscosity, and conductive heat transfer properties of functionalized carbon nanotube based nanofluids. J. Phys. Chem. C 2011, 115, 16737-16744. [CrossRef]

25. Sissons, J.; Kim, K.S.; Stins, M.; Jayasekera, S.; Alsam, S.; Khan, N.A. Acanthamoeba castellanii Induces Host Cell Death via a Phosphatidylinositol 3-Kinase-Dependent Mechanism. Infect. Immun. 2005, 73, 2704-2708. [CrossRef] [PubMed]

26. Siddiqui, R.; Saleem, S.; Khan, N.A. The effect of peptidic and non-peptidic proteasome inhibitors on the biological properties of Acanthamoeba castellanii belonging to the T4 genotype. Exp. Parasitol. 2016, 168, $16-24$. [CrossRef] [PubMed]

27. Khan, N.A.; Jarroll, E.L.; Paget, T.A. Acanthamoeba can be differentiated by the polymerase chain reaction and simple plating assays. Curr. Microbiol. 2001, 43, 204-208. [CrossRef] [PubMed]

28. Gabriel, S.; Rasheed, A.K.; Siddiqui, R.; Appaturi, J.N.; Fen, L.B.; Khan, N.A. Development of nanoparticle-assisted PCR assay in the rapid detection of brain-eating amoebae. Parasitol. Res. 2018, 117, 1801-1811. [CrossRef] [PubMed]

29. Khaliq, A.; Sonawane, P.J.; Sasi, B.K.; Sahu, B.S.; Pradeep, T.; Das, S.K.; Mahapatra, N.R. Enhancement in the efficiency of polymerase chain reaction by $\mathrm{TiO} 2$ nanoparticles: Crucial role of enhanced thermal conductivity. Nanotechnology 2010, 21, 255704. [CrossRef] [PubMed]

30. Abdul Khaliq, R.; Raed, K.; Hamzah Mohd, S.; Waleed Fekry, F. Enhancing the efficiency of polymerase chain reaction using graphene nanoflakes. Nanotechnology 2012, 23, 455106. [CrossRef]

31. Kong, H.-H.; Chung, D.-I. PCR and RFLP variation of conserved region of small subunit ribosomal DNA among Acanthamoeba isolates assigned to either A. castellanii or A. polyphaga. Korean J. Parasitol. 1996, 34, 127-134. [CrossRef]

32. Yousuf, F.A.; Siddiqui, R.; Subhani, F.; Khan, N.A. Status of free-living amoebae (Acanthamoeba spp., Naegleria fowleri, Balamuthia mandrillaris) in drinking water supplies in Karachi, Pakistan. J. Water Health 2013, 11, 371-375. [CrossRef]

33. Zhi, C.; Xu, Y.; Bando, Y.; Golberg, D. Highly Thermo-conductive Fluid with Boron Nitride Nanofillers. Acs Nano 2011, 5, 6571-6577. [CrossRef]

34. Nazarov, A.S.; Demin, V.N.; Grayfer, E.D.; Bulavchenko, A.I.; Arymbaeva, A.T.; Shin, H.-J.; Choi, J.-Y.; Fedorov, V.E. Functionalization and Dispersion of Hexagonal Boron Nitride (h-BN) Nanosheets Treated with Inorganic Reagents. Chem. Asian J. 2012, 7, 554-560. [CrossRef] [PubMed]

35. Lahiri, D.; Rouzaud, F.; Richard, T.; Keshri, A.K.; Bakshi, S.R.; Kos, L.; Agarwal, A. Boron nitride nanotube reinforced polylactide-polycaprolactone copolymer composite: Mechanical properties and cytocompatibility with osteoblasts and macrophages in vitro. Acta Biomater. 2010, 6, 3524-3533. [CrossRef] [PubMed]

36. Zhang, L.; Wang, X. DNA Sequencing by Hexagonal Boron Nitride Nanopore: A Computational Study. Nanomaterial 2016, 6, 111. [CrossRef] [PubMed]

37. Lin, Q.; Zou, X.; Zhou, G.; Liu, R.; Wu, J.; Li, J.; Duan, W. Adsorption of DNA/RNA nucleobases on hexagonal boron nitride sheet: An ab initio study. Phys. Chem. Chem. Phys. 2011, 13, 12225-12230. [CrossRef]

(C) 2020 by the authors. Licensee MDPI, Basel, Switzerland. This article is an open access article distributed under the terms and conditions of the Creative Commons Attribution (CC BY) license (http://creativecommons.org/licenses/by/4.0/). 